DOI: 10.21892/978-958-5547-64-3.4

\title{
4. Del daño ambiental al daño cultural en San Basilio de Palenque
}

\author{
Iván Vargas-Chaves ${ }^{1}$ \\ Alexandra Cumbe-Figueroa ${ }^{2}$ \\ Yina Torres-Pérez ${ }^{3}$ \\ Katy Torres-Pérez ${ }^{4}$ \\ Inés Cassiani-Hernández ${ }^{5}$
}

\section{Introducción}

En la generación de daños ambientales los derechos individuales y colectivos pueden verse vulnerados, cuando se trata de comunidades indígenas, tribales y afrocolombianas, por la forma en la que estas conciben la naturaleza y la íntima relación que existe entre el ambiente y sus planes de vida. Por lo tanto, ante la presencia de daños en el ambiente de estas comunidades puede generarse de forma desencadenante un daño cultural, porque estas poblaciones son las que pierden el escenario raigal y ancestral en el que desarrollan sus prácticas de identidad cultural.

Precisamente, en el presente texto se pretende discernir si ante la presencia de un conflicto ambiental en el Arroyo de San Basilio de Palenque, que a su vez es centro de las relaciones socioeconómicas, culturales y lúdicas de los miembros de esta comunidad, se logra desencadenar un daño cultural. Para esto, abordaremos en primer lugar, las consideraciones

1 Abogado de la Universidad del Rosario. Máster en Derecho de la Universidad de Génova, Italia. Máster en Derecho Privado de las Universidades de Salamanca, Pública de Navarra y de Venecia Ca' Foscari, España e Italia. Doctor en Derecho de la Universidad de Barcelona, España. Dottore di Ricerca (Dott. Ric.) de la Universidad de Palermo, Italia. Docente investigador de la Corporación Unversitaria del Caribe - CECAR.

2 Asistente de investigación.

3 Asistente de investigación.

4 Asistente de investigación.

5 Asistente de investigación. 
preliminares sobre el riesgo ambiental en el Arroyo, describiendo allí las prácticas, que eran costumbre realizar en estos lugares, tanto sociales como recreativas, y los factores ambientales que han influido para que la comunidad no las continúe llevando acabo.

En segundo lugar, haremos una aproximación del riesgo y del daño como concepto, para luego estudiar el daño material y el inmaterial, estableciendo la diferencia entre ambos, y los requisitos para que se constituya cada uno de ellos. Acto seguido, se examinará la noción de daño inmaterial cultural, donde se traerán a colación los aspectos intrínsecos de este concepto. Y finalmente, se desarrollará el tema del daño ambiental al daño cultural, tomando las variables específicas de cada uno, y haciendo el estudio del caso particular de San Basilio de Palenque.

Es importante destacar, a manera de aclaración, que la información consignada en este capítulo fue recolectada por el equipo de investigación en la comunidad de San Basilio de Palenque. En tal sentido, las fuentes se contrastan con el trabajo de campo llevado a cabo con líderes e integrantes de la comunidad a través de entrevistas. La metodología utilizada que respalda los hallazgos, se publicó en el documento titulado Pertinencia de la metodología de enfoque de Sistemas Socio-Ecológicos (SSE) para determinar los actores y sistema de gobernanza en un conflicto ambiental: Estudio de caso del arroyo de San Basilio de Palenque (Luna-Galván VargasChaves \& Guerra, 2019).

\section{Consideraciones preliminares sobre el riesgo ambiental en el Arroyo}

San Basilio de Palenque es un corregimiento del municipio de Mahates ubicado aproximadamente a una hora de la ciudad de Cartagena de Indias, en las faldas de los Montes de María. Es un pueblo de especial importancia por sus expresiones culturales, además del hecho de que fue el lugar en el que los negros que habían sido esclavizados y lograban escapar, se asentaban para formar allí sus comunidades, manteniendo desde aquella época expresiones como su lengua, forma de peinar, cocina típica, que los caracterizan hasta la actualidad. 
San Basilio de Palenque recibe su nombre por exigencia de sus habitantes, los cuales aclaran que el santo es del pueblo, y no el pueblo del santo, por lo que no aceptan que sea nombrado a la inversa. En este pueblo se manifiestan las expresiones culturales propias de los habitantes y tienen como punto focal el Arroyo. El Arroyo de San Basilio de Palenque atraviesa la comunidad de sur a norte, es la fuente hídrica de la población y se encuentra dividida por nombres, sectores y usos. Es llamado, por supuesto, dependiendo del sector que cruce, las condiciones físicas del mismo, o del nombre de los dueños de los terrenos que lo rodean. Por ejemplo, está el sector llamado Alberto, nombrado así por su ubicación cerca de los predios de una persona influyente con este nombre. En cuanto a los usos, se revela que depende de si es un lugar exclusivamente para hombres, para mujeres o mixtos.

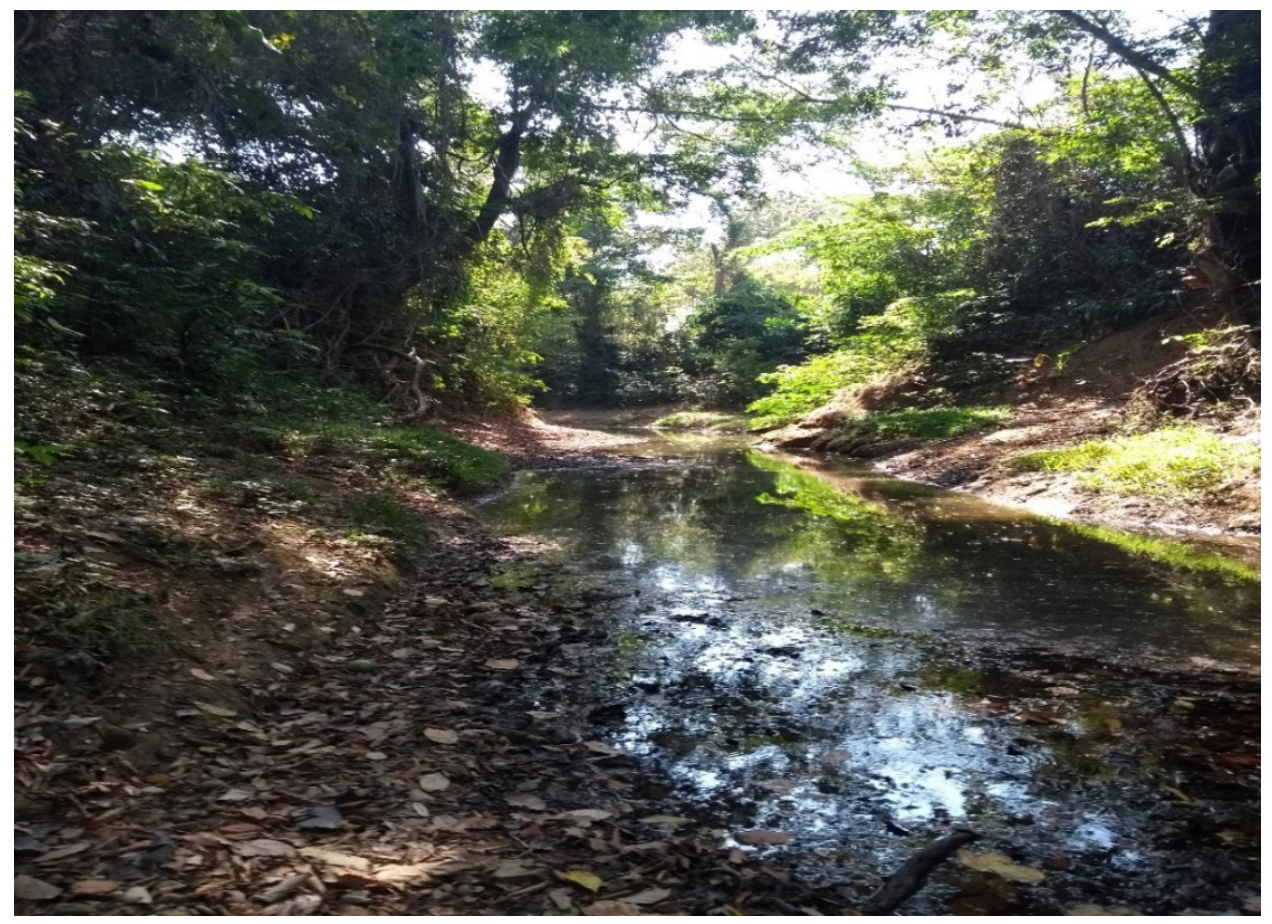

También las denominaciones de los sectores del Arroyo de Palenque se dan teniendo en cuenta los nombres de zonas montañosas, las condiciones físicas o el nombre de personas dueñas de predios que atraviesan o colindan con este. En la parte en la que el Arroyo nace, donde se desprende de la Serranía de Maco, hay un sector llamado "Casingui" que corresponde a 
todo un cumulo de territorios. El cruce de San Cayetano que corresponde al cordón comunicativo terrestre con la comunidad vecina de San Cayetano. La piedra es la zona nombrada así, por la abundancia de las mismas en el lugar. El sector Melchor debe su nombre a un señor que tenía sus terrenos en ese lugar. Al igual que Pellín, Alberto, Berre, etc. También se pueden encontrar casos en los que las pozas reciben nombres específicos, como es el caso de Los terneros, La anguilla, La larga, La poza de guácimo, chengue, entre otras.

\section{Arroyo de Palenque sector Melchor}

En los alrededores de la fuente hídrica se encuentran árboles de gran dimensión como el caracolí, arroyuelo, membrillo, guácimo, ceiba, bomba bruja, y guayacán. Al igual que arbustos ornamentales, tales como la guamita, el colicencio, cruceta, guardián blanco y solo hombre, que tienen menor tamaño y crecen en la parte inferior de los árboles, reconocidos por los palenqueros como los "policías" encargados de la vigilancia del arroyo.

Asimismo, es posible encontrar en sus orillas gran variedad de fauna, entre ellas, la iguana, el pasa arroyo, serpientes de diversas variedades mapana, víboras, toche, por ejemplo-; la guartinaja, animal que construye su cueva cerca de las orillas del arroyo o en los troncos que se dejan entrever de la tierra; las raíces de los grandes árboles de caracolí; diversas variedades de mariposas y lagartijas. Gran variedad de aves, como: chauchau, la cocinera, chelequita, pájaro vaco, garzas. En cuanto a los peces, está el moncholo, las sardinas, pachas, cirito, barbarito, guabino, macaco, chipi, y muchos más. 


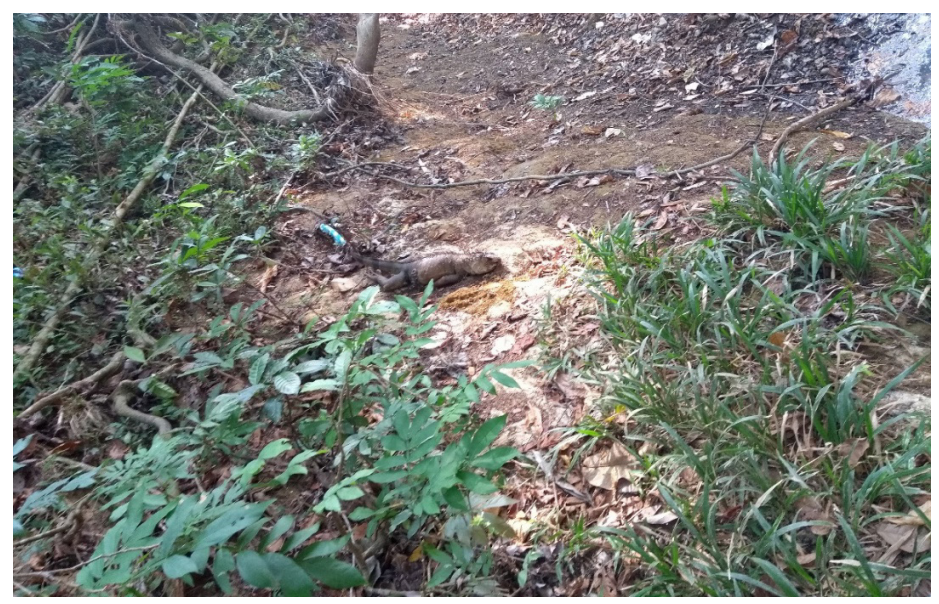

Iguana, fauna típica del sitio.

Por todo lo anterior, el Arroyo de San Basilio de Palenque es de una gran importancia para la comunidad, pues representa el centro de vida en la que se logra manifestar la cotidianidad cultural de los habitantes de este pueblo, ya sea como espacio recreativo, como comunicativo, de consulta y hasta de solución de conflictos.

En cuanto a la recreación y diversión, este es el sitio donde los Kuagros, que son jóvenes de la comunidad que se encuentran en un mismo rango de edad, y hacen parte del mismo sector del pueblo o que están cursando el mismo grado académico, se reúnen para realizar diversas actividades tanto en las zonas exclusivas para hombres, como en las de las mujeres, o en las áreas mixtas. Allí logran interactuar los Kuagros y entretenerse con juegos en las aguas como aprender a nadar o incluso medir fuerzas para determinar qué grupo es más fuerte y más popular.

Sobre este último punto, un miembro de un Kuagros reta a un miembro de otro grupo a un enfrentamiento a "puño limpio", de ahí se enfrentan físicamente frente a los miembros de los otros Kuagros hasta que hay un ganador, una vez se comprueba quién es el más fuerte, los jóvenes continúan con los juegos sin ninguna clase de resentimiento. Es en este lugar donde los jóvenes comparten sus más profundos secretos y sentimientos, incluso pueden indicar sobre el gusto que sienten por un chico o una chica, con la seguridad de que todo lo dicho queda protegido por la gran amistad que existe entre ellos. 
Ahora bien, las zonas mixtas del Arroyo eran el lugar ideal para dar inicio al cortejo sentimental por parte de los hombres, quienes le pedían ayuda a uno de los integrantes del Kuagros para que cuando llegará la mujer que les gustaba mantuviera una relación más estrecha con ella para hacerle "vuelta", actividad que consistía en ir hasta donde la mujer y entablar una conversación comentándole los sentimientos de su amigo. Este joven al que se encomendaba la labor era conocido como "vueltero", y tenía como misión comentarle a la mujer, cada vez que tuviera la oportunidad, los sentimientos de su amigo, así como llevarle frutas, cartas, mensajes y hablarle de lo bueno que era su amigo y de los beneficios de iniciar una relación con él.

El "vueltero" debía insistir todo lo que fuera necesario hasta que la joven accediera a hablar personalmente con su amigo y posteriormente entablara una relación con él, pues en ocasiones las jóvenes no eran muy fáciles de convencer. Una vez logrado que se iniciara el noviazgo, era el encargado de llevar recados y mediar en los posibles problemas que se pudieran suscitar en la pareja.

Las zonas mixtas del Arroyo tenían como ventaja que era allí precisamente donde, por lo general, se encontraban las "pozas", es decir, los lugares más profundos del Arroyo en los que se podía nadar. Además, había montículos que eran aprovechados por los jóvenes para subirse en la parte más alta y lanzarse desde allí para caer en las pozas, no sin antes hacer referencia con versos a situaciones cotidianas, vivencias, o decirle halagos a la chica de su gusto. Asimismo, las chicas también aprovechaban estos montículos, pero desde partes más bajas, desde donde expresaban sus pensamientos, dichos y refranes, que en ocasiones eran "puyas" (o retos) dirigidos a las demás personas que se encontraban en el lugar, y con las que no mantenían buenas relaciones.

En el mismo sentido, estas zonas del Arroyo eran escogidas por los jóvenes como sitios de reunión, en cuyas orillas realizaban los cocinados, para lo cual utilizaban ollas con alimentos que ellos mismos preparaban. No obstante, al pasar mucho tiempo en las pozas y por el lanzamiento desde los montículos, los ojos de los jóvenes se tornaban de color rojo, por lo que algunos padres prohibían a sus hijos bañarse en las pozas, orden que desobedecían y para tratar de ocultarlo, en el camino a casa cerraban sus manos, realizaban soplos en sus puños y luego se los llevaban a la cara, 
especialmente a los ojos con la convicción de que al hacer eso varias veces sus ojos perderían el tono rojo, y volverían a su color natural.

Otra actividad que se desarrollaba en el Arroyo era la pesca con anzuelo cordal, realizada por los hombres que acordaban asistir a este lugar. Para lo cual, antes de ir al Arroyo, cavaban unos pequeños agujeros en los patios de sus viviendas en busca de pequeñas lombrices de tierra para usarlas como carnada; luego de abastecerse de suficientes lombrices se reunían en la entrada de uno de los sectores del Arroyo con un sedal de tres o cuatro metros con un anzuelo en uno de los extremos.

Los hombres se sentaban calmados en las orillas de diferentes sectores del Arroyo que cambiaban cada cierto tiempo, a la espera de que un pez "picara" (tomara) la carnada y fuera pescado por los jóvenes. Los pescadores, por lo general, no llevaban consigo un recipiente para los peces, por lo que al llegar al Arroyo cortaban una rama en forma de gancho y allí los ensartaban. Una vez terminada la pesca, los jóvenes se iban a reunir en la casa de uno de ellos donde limpiaban el pescado y lo repartían, o también cocinaban un sancocho para todos.

El piñiqui era otra de las tantas actividades realizadas en este Arroyo. Tarea que consistía en capturar pájaros vivos con una rama ubicada en la parte alta de un árbol, la cual era cubierta con una sustancia elaborada con frutas de uvita, preparada por los jóvenes, que al machacarlas y mezclarlas se les agregaba azúcar y quedaba un líquido pegajoso y azucarado. Con ello, cuando los pájaros se posaban en la rama untada con esta sustancia quedaban atrapados, y los jóvenes subían al árbol para capturarlos y tenerlos como animales domésticos en sus hogares. 


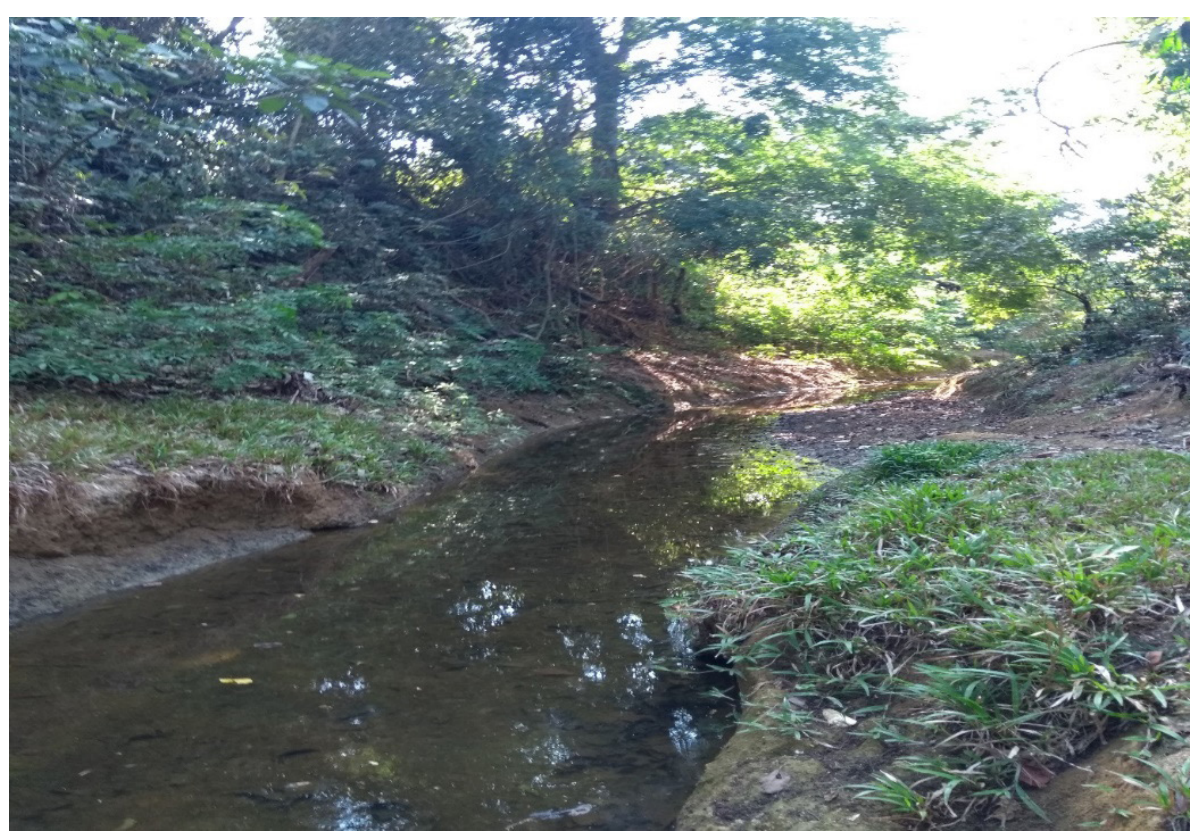

Arroyo de Palenque en el sector Alberto.

Asimismo, el Arroyo era un lugar que se destacaba porque representaba el sitio en el que se encontraban muchas personas para recolectar un poco de agua para bañarse o para lavar la ropa. Esta última labor era desarrollada por las mujeres de la comunidad, quienes se ubicaban por orden de llegada una tras la otra en la corriente de agua, tratando siempre de llegar temprano para ubicarse en el primer puesto, y así no recibir el agua usada de la ropa de las demás. En un día podían ir a reunirse cerca de 15 mujeres en el Arroyo.

Para lavar la ropa estas mujeres llevaban como instrumentos de trabajo, una tabla de aproximadamente un metro y veinte centímetros de largo con unos treinta centímetros de ancho; baldes, cepillos y manducos que era un pedazo de árbol en forma circular que va desde la punta de los dedos de la mano hasta el codo, cortado y moldeado por sus esposos, para golpear la ropa cuando estaba enjabonada, y así dejarla mucho más limpia.

La actividad de lavar la ropa se realizaba en las zonas de uso exclusivo para mujeres, y allí algunas de ellas solían despojarse de sus prendas de vestir para quedar en ropa interior. Por lo que cuando un hombre deseaba pasar por ese lugar, bien sea porque por este camino se encontraba un 
sendero hacia sus predios de siembra o porque iba a llevarle el alimento a alguna de las mujeres, que por la premura de llegar al Arroyo no había comido en su casa, sin importar si era niño, adolescente o adulto debía detenerse antes de llegar al sitio y gritar a viva voz: ¡Ahí va hombre! Tenía que esperar hasta que las mujeres le dieran el visto bueno de llegar hasta donde estaban ellas. En caso afirmativo, las mujeres que estuvieran en ropa interior se cubrían y ahí entonces le gritaban al del sexo masculino que sí podía entrar al Arroyo.

Este era un ritual realizado para mantener la privacidad de las mujeres y el hombre que no lo cumpliera y llegara a las zonas de uso de las mujeres sin darles tiempo para que se cubrieran era visto como mal educado y morboso. Esto era muestra del respeto hacia las mujeres y de los buenos modales del hombre. Esta costumbre también se aplicaba en sentido contrario, cuando era la mujer quien iba a cruzar por los sectores exclusivos de los hombres.

En virtud de esto, y de las varias horas que podía tomar el lavado de la ropa, las mujeres aprovechaban este tiempo para contar anécdotas de su vida, chistes y hablar sobre los acontecimientos ocurridos durante los últimos días en el sector donde vivían o en el pueblo. Era de esta manera que las mujeres se enteraban de quienes habían llegado recientemente a la comunidad, quiénes se habían mudado de la zona, las nuevas parejas, quiénes se habían ido a vivir juntos, quiénes se habían separado, los eventos que se iban a realizar e incluso recibían allí la invitación para los mismos. De modo, que este lugar era el principal escenario de comunicación del pueblo, o para decirlo en palabras de un palenquero "Si usted quiere saber sobre algún suceso en la población, diríjase al arroyo que allí se entera".

En lo que se refiere al momento del baño, las mujeres que no querían bañarse con el agua que fluía directamente de la corriente porque estaban turbias por el juego de los niños o por simple decisión personal, realizaban casimbas, que son pequeños agujeros en las orillas separados unos centímetros de la corriente y de los cuales emana agua. Como era costumbre ir a bañarse en pequeños grupos, las mujeres ordenaban turnos para la realización de la casimba y la extracción de agua de las mismas. Pero si en dado caso, al llegar al Arroyo ya había una casimba hecha, la achicaban, esto es, le sacaban el agua que tenía y esperaban a que se llenara nuevamente. 


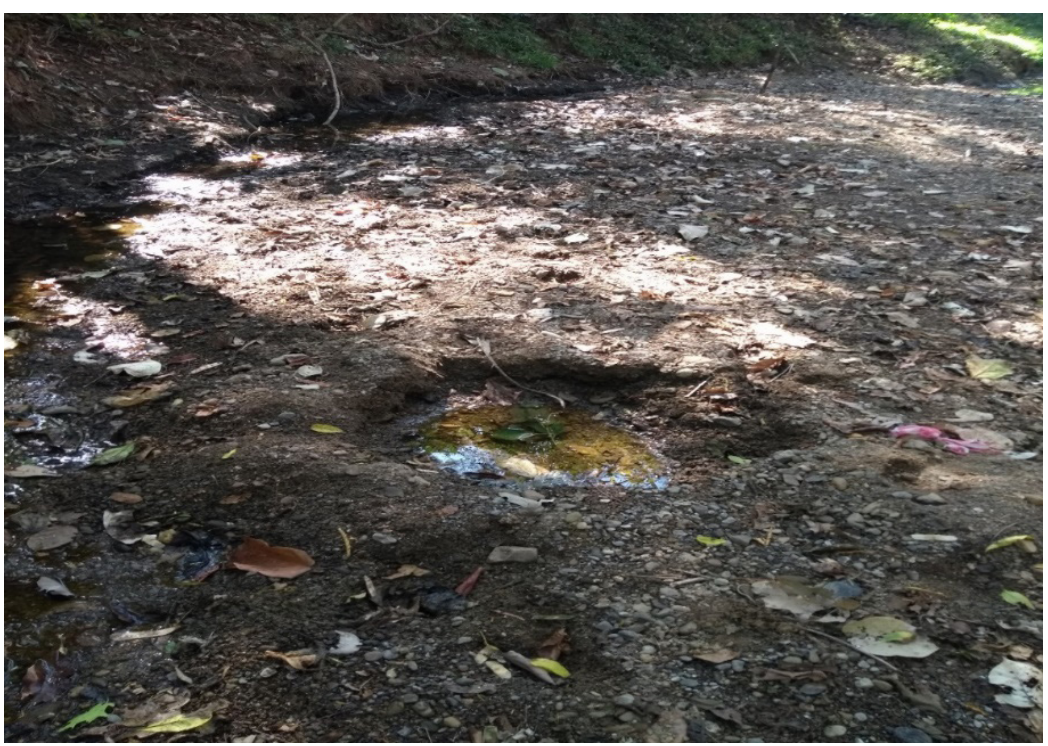

Casimba hecha por mujeres en el Arroyo de San Basilio de Palenque

Por otro lado, cuando la comunidad palenquera iba a utilizar agua del Arroyo para el consumo humano, se abría un agujero en las orillas a una profundidad aproximada de un metro, metro y medio o también de dos metros, dependiendo de la temporada del año. Una vez hecho esto, se sacaba toda el agua sucia por la excavación y se esperaba hasta que se llenara de agua nuevamente, y esta era la que se sacaba para llenar los tanques y llevarla a las casas de los habitantes de la comunidad. En ocasiones, era tanta la cantidad de personas que iba por agua de estos aljibes, que se establecía un sistema de turnos para llenar el agua, asignando un número máximo de baldes que podía llenar una persona en cada turno.

Además de esto había una regla básica en la comunidad para realizar esta tarea como era la de que el agua debía ser recogida por una persona adulta, porque se tenía la creencia de que los niños o adolescentes carecían de la suficiente experiencia y diligencia para el llenado, por lo que podían ensuciar el agua. Una vez que estaban los baldes llenos de agua, las personas los llevaban a su casa en el lomo de un animal o en forma grupal por los Kuagros.

La cosmovisión de la comunidad palenquera está basada en creencias mágico religiosas, divididas y organizadas en varios mundos. El mundo de los vivos basado en las prohibiciones y reglas de conducta para la construcción 
de la vida correcta. También está el mundo de los muertos que es lugar en el que se reúnen los palenqueros con sus antepasados. Y, por supuesto, está el Arroyo que representaba un mundo opuesto para Palenque, pero no el Arroyo en su dimensión total sino unos lugares específicos donde se podía concebir la vivienda del ser opuesto al palenquero, que realizaba todo lo contrario a lo que ocurría en el mundo de los vivos. Este era el mundo del Mohán, un sitio mítico que se encontraba debajo de las aguas de las fuentes hídricas que recorren la población, ubicada una al este y la otra al oeste. Este sitio era habitado por unas criaturas vestidas de blanco, que denominaban mohanes, mohanas y mohansitos, quienes físicamente eran descritos como seres de un metro de altura, cabello negro muy largo y liso, nariz fina, labios delgados, ojos verdes, con los pies invertidos, es decir, los dedos hacia atrás y los talones hacia adelante. Estas criaturas no comían azucares, ni sal, y acostumbraban curarse con plantas, y hacer el amor a través de la barriga y no con sus genitales.

Según la cultura palenquera estos seres abundaban en las pozas o pozos muy profundos, en los sitios más desolados de la comunidad. Las personas no podían ir solas a estos lugares a bañarse, siempre tenían que estar en compañía de tres personas como mínimo, y en un horario determinado, que no podía ser a las 6 am, 12 del mediodía, 6 de la tarde, ni en horas nocturnas, y tampoco en los días jueves y viernes santo, porque a estas horas y en estos días, era cuando dichos seres se reunían para dialogar.

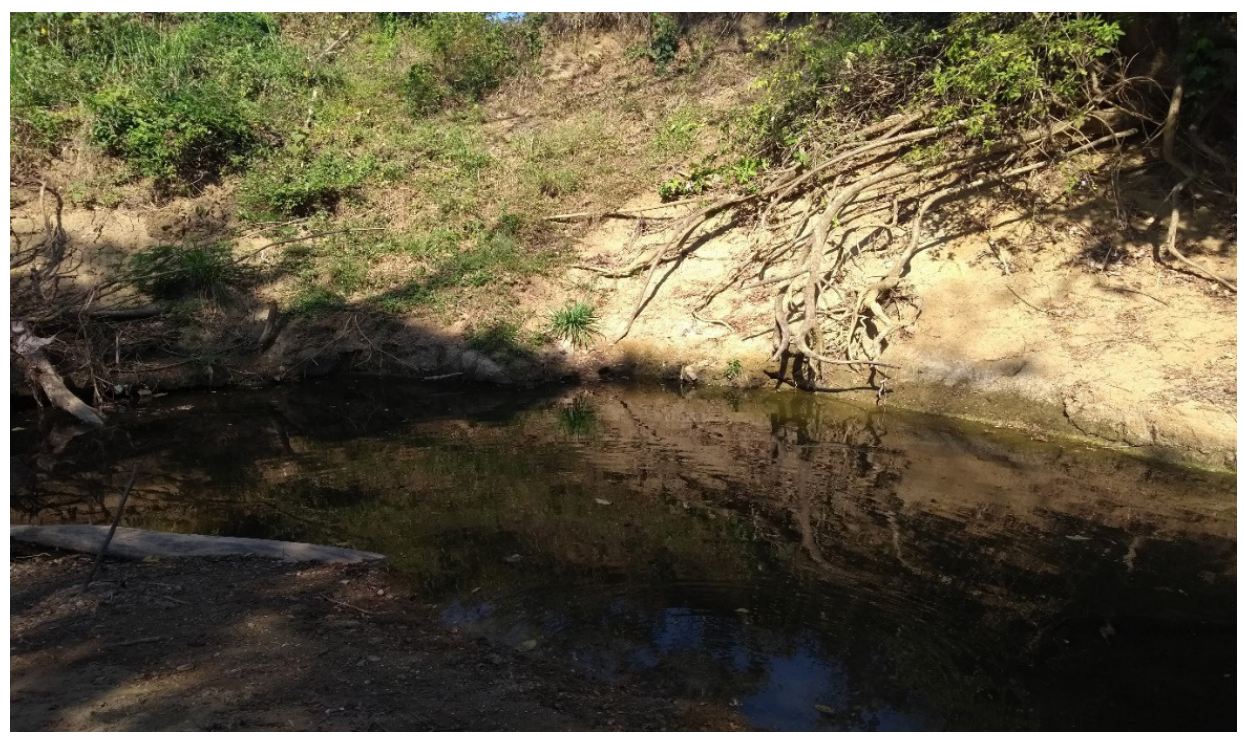




\section{Poza profunda}

Sumado a la regulación del horario para el uso del Arroyo por la creencia en estos seres, también se creía que los mismos podían llegar a enamorarse de una persona del mundo de los vivos, y que podía hacer que esta persona fuera llevada a este mundo debajo de las aguas del Arroyo por el mohán o la mohana, los cuales se presentaban ante la persona de su afecto, pero con esto sólo lograban que la persona los evitara, porque ya conocía de su apariencia misteriosa y rara.

Estas criaturas con sus poderes sobrehumanos lograban presentarse ante el palenquero en forma de planta, animal o de persona que pudiera interesarles. Por ejemplo, parecerse a sus tíos, primos o cualquier familiar de su confianza; también solían transformarse en personas del sexo opuesto para lograr enamorarlos y así llevárselos a su mundo, donde todo queda al revés: los tejados de las casas están en los suelos y los pisos funcionan como tejados. Allí, la persona que fue llevada bajo engaños conocía el verdadero aspecto físico de su enamorado -un mohán o una mohana-. Por lo general, esa persona no quería permanecer en ese mundo, por lo que debía evitar comer lo que el mohán le brinde, porque era con la ingestión de alimentos que se sellaba el trato que obligaba a la persona a quedarse allí para siempre.

Para que la persona pudiera regresar al mundo de los vivos, ella y sus familiares debían cumplir con lo siguiente: primero, no ingerir los alimentos que le brindara el Mohán; segundo, debía estar bautizada, lo cual llevaba a que sobre la madrina recayera una tarea muy importante, y es que frente a la iglesia del pueblo esta debía a diario gritar fuertemente el nombre de la persona que se encontraba en el mundo mágico del Mohán, esta acción le generaba una gran incomodidad al Mohán y lo llevaba a tomar represalias contra la persona cautiva, como someterla a pellizcos y rasguños. Y era tras la insistencia del llamado de la madrina que el Mohán decidía liberarlo en busca de su tranquilidad, pero lo hacía en un sitio alejado y poco transitado por la comunidad.

Pese a esto, se tiene que aclarar que estos seres no se presentaban en el mundo de los vivos únicamente para hacerles maldades o llevárselos a su mundo, sino que también traían beneficios para la comunidad palenquera con sus rezos, su conocimiento en plantas medicinales. Además, cuando se enamoraban de una persona del mundo de los vivos, en lugar de llevarla a su mundo, le obsequiaban riquezas y conocimientos. 
Ahora bien, lo anteriormente expuesto da muestra de los diferentes usos que los habitantes de San Basilio de Palenque le daban al Arroyo, constituyéndose en prácticas culturales inherentes a esta comunidad, que se han visto afectadas por factores externos como la falta de presencia estatal, pues la misma ha desencadenado en que en el lugar haya presencia de residuos y basuras que logran desincentivar que los habitantes de esta zona sigan acudiendo al Arroyo para desarrollar todas las actividades señaladas. Esta situación ha llegado a permear las convicciones e idiosincrasia de esta población, en cuanto a que han dejado de creer en la existencia de su mitología y de sus mundos descritos anteriormente, reduciendo su cosmovisión particular.

\section{Del riesgo al daño como concepto}

El avance de la sociedad ha traído consigo nuevas necesidades y exigencias que deben ser cubiertas por el ordenamiento jurídico en tanto existe un contrato social entre los ciudadanos y el ordenamiento. Donde los primeros se comprometen a estar sujetos a la regulación del segundo. Un tema que no ha podido excluirse de esta realidad es la responsabilidad civil, porque a medida que avanza la sociedad, surgen nuevas actividades con potencialidad de daño, que le exigen al conocimiento del derecho estar a la vanguardia y regular estos posibles escenarios adversos.

Por lo tanto, este desarrollo de la sociedad exige dinamismos normativos, porque surgen problemáticas relativas al aprovechamiento de la naturaleza y el desprendimiento del ser humano de las obligaciones tradicionales, para pasar a aquellas provenientes de las derivaciones del desarrollo técnico-económico. A medida que progresan sectores de la sociedad, crecen dos factores contradictorios: la promesa de seguridad y los riesgos, estos últimos entendidos como las situaciones de peligro o amenazas, autoprovocadas por los actores sociales que pierden la racionabilidad en sus actuaciones (Beck, 1998).

De acuerdo con Beck (1998), hay que subrayar el riesgo que está en el resultado de la posición moderna de previsión y control respecto de los futuros resultados de las acciones humanas, las cuales son rechazadas en la sociedad moderna, a causa de los daños irreversibles que pueden generar 
porque lleva siempre consigo el tema de la responsabilidad del causante. En cambio, el daño desencadenante del riesgo en materia ambiental hace referencia a toda alteración relevante de carácter negativo en el ambiente, los recursos naturales, los ecosistemas o bienes colectivos (Cafferatta, 2009).

Es así como al hacerse más latente la ocurrencia del daño, le asiste al ordenamiento jurídico el deber de fijar una obligación resarcitoria en favor del que se ve perjudicado por este daño. No en vano la responsabilidad civil se encarga de que el desagravio se haga de manera tal que la reparación se ajuste al estado de cosas anterior a la ocurrencia del daño y que, a su vez, es entendido como toda afrenta a los intereses lícitos de un sujeto de derecho.

(...) trátese de derechos pecuniarios o de no pecuniarios, de derechos individuales o de colectivos, que se presenta como lesión definitiva de un derecho o como alteración de su goce pacífico y que, gracias a la posibilidad de accionar judicialmente, es objeto de reparación si los otros requisitos de la responsabilidad civil -imputación y fundamento del deber de reparar- se encuentran reunidos (Henao; 2015).

De hecho, y siguiendo a Henao (2015), podemos aseverar que la existencia del daño cuenta con una serie de elementos que inciden directamente en la reparación del mismo:

(i.) La lesión puede ser causada a derechos individuales o colectivos. Este elemento tiene gran relevancia en la reparación de la lesión, toda vez que es diferente resarcir el daño a personas individualmente consideradas -naturales o jurídicas- que a una colectividad. En el segundo caso se entra a analizar si los intereses del grupo son un objeto divisible o indivisible.

(ii.) La simple amenaza de ocurrencia del daño, sobre la que el propio Henao (2015) advierte que no es necesario la consumación de la lesión, sino que con la sola alteración del goce pacífico del interés lícito o no, contrario a derecho, se presenta un daño. 
(iii.) El perjuicio sobre intereses pecuniarios y no pecuniarios, que hace referencia a la naturaleza económica del interés perjudicado, en el entendido que cuando se lesionan derechos de orden pecuniario, la reparación debe ser de naturaleza económica. Pero, en tanto "que la reparación de los derechos no pecuniarios puede revestir formas diferentes de la económica, advirtiendo que cuando se otorga una suma de dinero la misma no equivale al daño sufrido sino a su simple compensación" (Henao, 2015).

Respecto de esto último y debido a que los derechos pecuniarios -también denominados por este autor derechos materiales -tienen un valor de cambio en el mercado, lo cual no ocurre con aquellos derechos no pecuniarios $-\mathrm{o}$ derechos inmateriales-. En el caso de la reparación a las colectividades, al ser los intereses colectivos divisibles, pese a estar protegidos de manera homogénea, tienen un carácter subjetivo particular en cada persona. Diferente son los intereses protegidos en las acciones populares que comportan un carácter unitario para la colectividad, sin que una persona pueda ser excluida de su goce por otras ( $C f$. Constitución Política de Colombia, art. 88).

\section{Del daño material al daño inmaterial}

El daño puede ocasionar diferentes tipos de perjuicios, de ello depende que sea pecuniario o no, en tanto sea daño material o daño inmaterial. Entendiendo al primero como el perjuicio que afecta a bienes de naturaleza económica, y que es posible subdividir en daño emergente y lucro cesante.

Así lo ha reconocido el Consejo de Estado en Sentencia de 27 de noviembre de 1990, al establecer "(...) en relación con la cuantificación de los daños materiales, en primer lugar, se observa que estos se clasifican como emergentes y como lucro cesante. En los primeros se comprenden los intereses patrimoniales actuales que han sido afectados con el hecho del cual se deriva la responsabilidad; en los segundos, el interés futuro o la utilidad futura que por la misma razón el afectado dejará de percibir." Lo cual es aplicable tanto para reparación en materia de responsabilidad civil contractual como extracontractual 
Resulta entonces que la reparación del daño emergente tiene lugar en los eventos en los que se demuestra la existencia de un detrimento patrimonial. Esto es una salida del patrimonio -en el presente o futurobien sea de una persona o de una colectividad. Caso diferente es el lucro cesante, que se debe cuando se demuestra "una pérdida de expectativa de riqueza, de utilidad, de ingreso, de crecimiento patrimonial en el sentido que el objeto del daño es un interés futuro, es decir, un interés relativo a un bien que todavía no corresponde a una persona" (Mancipe, 2005).

Por otro lado, está el daño inmaterial, también conocido como extrapatrimonial o moral, que tiene como gran dificultad en su aplicación, la falta de definición derivada de la subjetividad de los intereses perjudicados. Para Tamayo-Lombana (1997) el "daño moral vulnera los derechos de la personalidad: integridad, estética, imagen, pudor, creencias, honor, derecho al nombre y a la privacidad; o las libertades individuales: derechos de movimiento, de residir, de reunirse, de opinar, de religión, de empresa, de trabajo, lo mismo que los derechos de familia, profesionales, cívicos, políticos".

En otro sentido, Henao \& Pérez definen el daño inmaterial como "los perjuicios que no tienen una naturaleza económica, en el sentido de que, por definición, no se les puede medir en dinero. Distinto, como ya se vio, es lo que ocurre con el daño material en donde se puede encontrar un valor de reemplazo".

Lo cierto es que si bien el daño inmaterial no comporta un perjuicio material compensable en dinero, de acuerdo con los actuales sistemas jurídicos de responsabilidad, resulta que viene siendo compensado económicamente. Esto, por el avance legislativo alrededor del mundo, que dejó de consagrar, como modo de reparar el daño causado, el infringir el mismo perjuicio a quien lo ocasionó contenido en el Código de Hammurabi (art. 196 "si un hombre deja tuerto a otro, lo dejarán tuerto"), para pasar a las compensaciones monetarias.

Y aunque se resarza el daño por medio de una compensación económica, esta indemnización no tiene la misma naturaleza que la reparación de daño material, porque lo que realmente se pretende es dar a la víctima una posible satisfacción que atenúe el perjuicio ocasionado. En cambio, la reparación material se limita a otorgar una compensación 
de bienes que no tiene como objetivo reemplazar o suplir una aflicción (Barrientos Zamorano, Marcelo; 2008). De manera que la indemnización del daño extrapatrimonial, tiene por objeto ofrecer un enriquecimiento patrimonial a la víctima del daño para mitigar el perjuicio causado al derecho extrapatrimonial (Ternera Barrios Luis \& Francisco; 2008).

\section{Elementos del daño}

Doctrinal y jurisprudencialmente se han establecido 3 condiciones para que un daño sea objeto de reparación, ya sea material o inmaterial:

1. Que sea directo, en cuanto a la relación de causalidad entre una situación y sus causas. Es el nexo causal, la relación jurídica entre la causa y el efecto.

2. Que sea cierto, lo cual se refiere a la veracidad del daño "El juez debe estimar como evidente el actual o futuro empobrecimiento patrimonial o la actual o futura trasgresión de un derecho extrapatrimonial". (Ternera Barrios Luis \& Francisco; 2008).

3. Que sea legítimo, en cuanto a que el derecho lesionado esté protegido por el ordenamiento jurídico.

\section{El daño inmaterial-cultural}

Dentro del ordenamiento jurídico colombiano no existe una definición sobre lo que es el daño cultural, entre otras razones, porque es un campo jurídicamente poco explorado. Sin embargo, sí es posible hallar una fuerte protección a las diversas manifestaciones culturales de las distintas comunidades étnicas del país, lo cual permite que los perjuicios causados a estas no pasen desapercibidos y comiencen a volverse objetos de estudios.

Para comprender ¿Qué es el daño cultural y cómo se produce? Es precio tener clara la noción de cultura que, de acuerdo con la Corte Constitucional colombiana en Sentencia C-224 de 2016, significa el conjunto de rasgos y características espirituales, materiales, intelectuales y afectivas de una comunidad o grupo social, y que abarca no sólo las 
expresiones artísticas sino los modos de vida, formas de convivencia, sistemas de valores, creencia y tradiciones.

En ese sentido, existe daño cultural cuando hay una pérdida de costumbre e identidad de la sociedad en que se produce, tanto de manera individual como colectiva (Muñoz, Gloria, 2014). En el documento Tejiendo Derechos, se advierte que el menoscabo cultural de una sociedad trae, como consecuencias, el detrimento en la memoria histórica cultural, pérdida de la lengua, saberes, ritos, ceremonias y aspectos como la medicina tradicional. Así, cuando el agravio se produce en relación con el territorio de la colectividad se afecta la relación espiritual con este, causando, inclusive, la profanación de lugares sagrados. Se produce una ruptura de las cosmovisiones y el ciclo reproductivo de la cultura autóctona, formas de educación propia, organización económica y política.

Por regla general, el daño cultural se produce en el marco de una confrontación entre culturas en las que hay una dominante y otra débil, la cual termina subyugada frente a la primera que es por lo general de tipo foránea. Hecho que se ve favorecido por la falta de protección estatal y de comprensión y reconocimiento de las diferencias por parte de la cultura impositiva, rechazando la visión del mundo y estilo de vida de la cultura social más frágil (Muñoz, Gloria, 2014). Ahora bien, dentro de la clasificación clásica del daño entre material e inmaterial, el daño cultural pertenece a la segunda categoría, acercándose al concepto de daño moral.

Entendiendo el daño moral como el sufrimiento, dolor, angustia, padecimientos que influyen en el estado espiritual de la víctima del hecho dañoso, y sus elementos son: a) La afectación de un individuo determinado; b) De derechos personalísimos como la honra y dignidad; c) La reparación es de carácter ideal y no real; d) Es de tipo subjetivo (Cabezas, 2007).

Por su parte, el daño moral colectivo comprende la afectación de un número plural de valores propios de un grupo de personas, vinculadas subjetivamente y la lesión a un interés difuso que afecte a todos, y cada uno de los miembros del colectivo. En este daño grupal, el elemento personalista se ve desdibujado (Cabezas, 2007). Así, de acuerdo a la jurisprudencia de la Corte Interamericana de Derechos Humanos (caso Mayagna Awas Tingni Vs. Nicaragua, y, caso Efraín Bámaca Vs. Guatemala) esta nueva clase de daño inmaterial no es de tipo moral, sino que está acompañada del 
mismo, en la medida en que se experimenta un sufrimiento y depresión, por parte del grupo social. De modo tal, que el bien jurídico lesionado no es la honra ni dignidad, sino la existencia y vida misma del pueblo que sufre el perjuicio, por el menoscabo de sus creencias, cosmovisiones y estilo de vida, siendo esta lesión la que causa el daño moral.

Otro aspecto destacable, según Cabezas, es la asociación de este daño con algunos de tipo socio-ambientales, y su producción continuada en el tiempo, que conlleva a la asimilación de la cultura dominante por parte de la comunidad que se encuentra privada de la práctica de sus costumbres y condiciones de pertenencia a su propia comunidad. Caracterizar y determinar el daño cultural resulta importante para los efectos de establecer el tipo de reparación. Para Henao la reparación es la manera como el responsable cumple la obligación de subsanar ya que asegura a la víctima el retorno al statu quo antes del acaecimiento del daño. Este autor, nos dice, además, algunas de las formas más notables de reparación entre las que se encuentran: a) La reparación pecuniaria: entendida como la suma de dinero que se entrega a la víctima por el daño ocasionado, asemejándose este a unidades monetarias; b) La reparación in natura o reparación en especie, que consiste en la reparación a través de cualquier otro medio que no sea en sumas de dinero, y que busca que las cosas vuelvan al estado anterior en el que la víctima se encontraría, si el hecho dañino no se hubiese producido.

En cuanto al concepto de reparación del daño cultural, de acuerdo al texto Tejiendo Derechos, se tiene que esta debe propender por la recuperación y restablecimiento del equilibrio y armonía. Procurar por la garantía de permanencia física y cultural, y la reproducción de los sistemas culturales con autonomía, "con ella, se busca llenar los vacíos que quedaron luego de violaciones graves a los derechos de una persona, una comunidad o de un pueblo". Es bajo ese tenor que surge la pregunta de ¿Cuál es la forma más idónea de reparar el daño cultural? ¿Las formas tradicionales de reparación resultan adecuadas? Al respecto, en el documento antes mencionado, se dan algunas pautas para tener en cuenta.

Lo primero es saber que solo las comunidades que se están viendo afectadas conocen con exactitud el daño que se les está ocasionando. En ese sentido, solo ellos saben qué medidas podrían resultar efectivas para su reparación, siendo necesario en este caso, que se aplique el derecho 
fundamental de consulta previa, consentimiento libre, anterior e informado, establecido en el artículo 76 de la ley 99 de 1993.

Esto bajo el entendido de que los daños se reparan de acuerdo al estudio de cada caso particular ya que cada comunidad es rica en cultura y costumbres propias. Por tanto, el daño que se produce a cada una de ellas deber ser reparado conforme a ello y no es posible establecer un modelo único de reparación de daño cultural, sino que cada pueblo debe ser reparado de conformidad con sus necesidades. Si bien, en la reparación cultural se tiene un enfoque colectivo que contribuya al fortalecimiento e integración del pueblo, también es posible que los grupos étnicos decidan internamente reparaciones individuales, siempre y cuando lo lleguen a solicitar (Procuraduría General de la Nación).

Entonces, la reparación se materializa en una serie de medidas específicas, únicas para cada comunidad, debido a las distintas formas de daños y reparación que se pueden presentar. Así, por ejemplo, puede darse la restitución, usada en su mayoría en casos de pérdidas territoriales ancestrales, sobre los cuales la población tiene una relación colectiva y lo usan de una manera específica, teniendo las autoridades la obligación de titular estos territorios, sanearlos, ampliarlos y protegerlos contra intervenciones de terceros.

Otra medida es la indemnización, que no resulta procedente en todos los casos, puesto que los daños son generalmente invaluables, y no compensables en dinero. Pese a eso, es posible otorgar una indemnización colectiva para la constitución de proyectos para el fortalecimiento comunitario, educativos y de recuperación cultural.

También están las medidas de satisfacción, que incluyen el reconocimiento de las injusticias, el derecho a conocer la verdad, causas y circunstancias que permitieron el daño, así como las formas de reparación, garantías de no repetición con sanciones a funcionarios que posibilitaron el daño, sensibilización a la sociedad civil para la aceptación de diferencias, creación de vías fáciles para la reclamación de los derechos del grupo social. Pudiendo entonces, aplicar las formas de reparación tradicionalmente conocidas, usadas en ciertos eventos, pero conjugadas con nuevas formas de reparación. 
El tema de la reparación en daños culturales es un campo que se empieza a estudiar y presenta desafíos. Lo cierto es que bien se expresa en la cartilla Tejiendo Derechos que "pueden contribuir a enfrentar situaciones de despojo cultural y a fortalecer los elementos que han sido debilitados".

\section{Del daño ambiental al daño cultural}

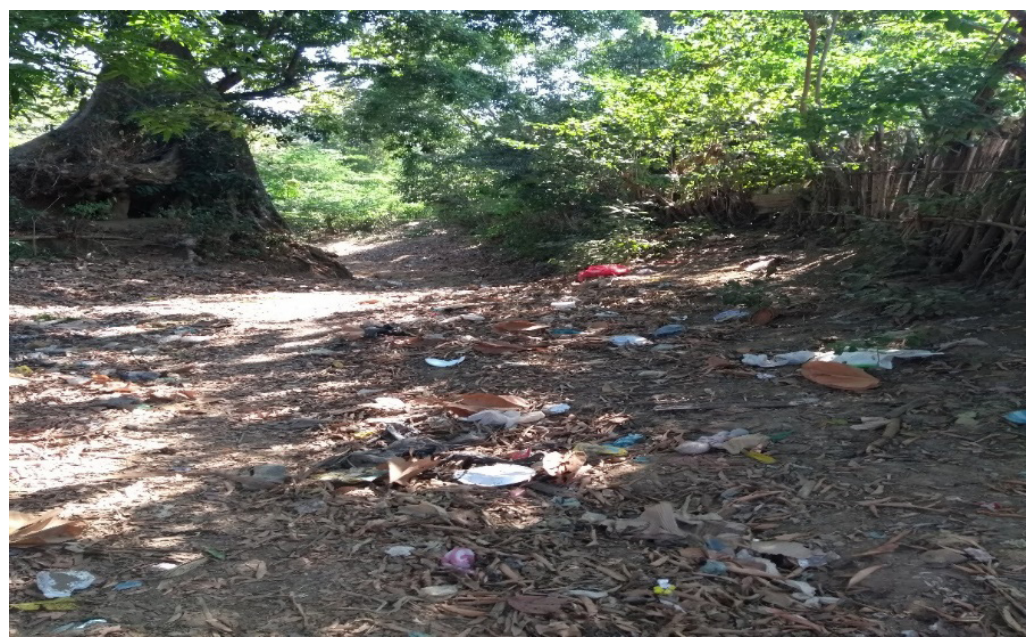

Entrada al Arroyo en el sector Caballito.

El daño, como lo indica Henao (1998) es la aminoración patrimonial -material e inmaterial- sufrida por la víctima, que puede ser tanto individual por la vulneración de los derechos subjetivos, así como respecto a los derechos colectivos. En materia ambiental es la afectación negativa relevante del ecosistema, los recursos naturales o el ambiente (Cafferatta, 2009) o como lo define el artículo 42 de la Ley 99 de 1993, la afectación del normal funcionamiento de los ecosistemas o de la renovabilidad de sus recursos y componentes.

De tal suerte, de acuerdo con las características de las actividades que solían realizar los habitantes de San Basilio de Palenque en el Arroyo, representaba un espacio central en las actividades domésticas, recreativas y socioculturales de la población. Por lo que existe una íntima relación entre los individuos y esta fuente hídrica, y como lo ha sentenciado la Corte Constitucional al analizar un caso similar, esto conlleva a que existe "un 
fuerte sentimiento de pertenencia lleno de valores simbólicos, territoriales y culturales" (Corte Constitucional, Sentencia T 622 de 2016).

La Corte ha logrado discernir a lo largo de su jurisprudencia ${ }^{6}$ que los pueblos indígenas, tribales y afrocolombianos conciben el territorio y la naturaleza de una manera diferente en comparación como lo hace la cultura occidental, pues para estas comunidades el territorio guarda íntima relación con su cosmovisión y subsistencia, por sus implicaciones religiosas, políticas, sociales, económicas y recreativas, y resulta más que un objeto de su dominio, ser un elemento esencial de los ecosistemas y la biodiversidad con la que interactúan en su cotidianidad. Razón por la cual se reconocen los derechos de posesión y dominio del territorio de manera colectiva, para garantizar la existencia de los pueblos en sí.

De ahí que cuando nos detenemos a examinar lo que este alto Tribunal ha denominado como Constitución Cultural, es posible dar cuenta de que se refiere a las disposiciones de la Carta superior relativas a la protección del patrimonio cultural de la nación; "en tanto que éste constituye un signo o una expresión de la cultura humana, de un tiempo, de circunstancias o modalidades de vida que se reflejan en el territorio, pero que desbordan sus límites y dimensiones" (Corte Constitucional, Sentencia T 622 de 2016). Lo que lleva entonces a que el Estado garantice la protección del patrimonio cultural tanto en el presente como en el futuro, haciendo parte de la identidad de un grupo social dentro de un momento histórico. Además, la Corte Constitucional ha dictaminado que el daño ambiental puede causar un impacto cultural, reflejado en la perturbación del desarrollo normal de las costumbres de cierta comunidad (Corte Constitucional, Sentencia T 691 de 2011).

Por supuesto, esto responde a políticas de inclusión de las minorías, desarrolladas desde diferentes campos. Por una parte está el Convenio 169 sobre pueblos indígenas y tribales de 1989 de la Organización Internacional del Trabajo -OIT- que entre todas sus disposiciones incluye en el artículo 2 el deber de los gobiernos de desarrollar acciones tendientes a proteger los derechos sociales, económicos y culturales de los pueblos tribales e

6 Corte Constitucional, sentencias T-652 de 1998, SU-383 de 2003, T-955 de 2003, T-547 de 2010, C-595 de 2010, T-693 de 2011, T-384A de 2014, C-449 de 2015, T-622 de 2016. 
indígenas y a garantizar su integridad. Bajo el respeto de su identidad social y cultural, de sus tradiciones y costumbres, y de sus organización social y política. Asimismo, en su artículo 5, consagra que para la aplicación del convenio debe tenerse en cuenta el reconocimiento y protección de los valores y prácticas culturales, sociales, religiosas y espirituales, propios de estos pueblos, así como sus problemas colectivos e individuales.

Por otra parte, se encuentran los postulados doctrinarios, donde Kymlicka (1996), expone que la idea del liberalismo que se apoya en viejos dogmas, resulta incapaz de entender y responder de forma adecuada a una realidad que se escapa de las teorías académicas, según la cual la construcción del Estado debe hacerse bajo la idea de la unificación de un grupo de personas con la misma visión del mundo y que persiguen los mismos fines. Pues, frente a las minorías etnoculturales es inaceptable adoptar las mismas políticas, en razón de que estos esperan proteger y conservar sus propios intereses, que se encuentran fundados en su cosmovisión inseparable de la naturaleza. Entonces, la forma de manejarlo es por medio de la adopción de políticas multiculturales, donde se les garanticen sus derechos, y sea así como se limite la construcción de nacionalidad estatal sobre las minorías que cuentan con una identidad propia.

Estas políticas multiculturales encuentran coherencia con los principios de libertad y justicia social, toda vez que permite la conservación de la identidad multicultural, y consecuentemente el cumplimiento de los derechos individuales de las personas que integran estos grupos. De modo que el reconocimiento por la diversidad cultural hace parte de una política obligatoria para los Estados democráticos liberales, en tanto, busca la protección y conservación de grupos étnicos compuestos por personas que comparten una cosmovisión propia, y que por ser minorías se encuentran en desventaja frente al resto de la sociedad (Sánchez-Botero, 1998).

Así las cosas, el reconocimiento de la diversidad cultural por vía constitucional resulta una forma de establecer políticas de inclusión en estos grupos históricamente marginados de la estructura social y política de un Estado. De esta manera fue como lo hizo el constituyente colombiano al incluir diferentes disposiciones que buscan reivindicar y proteger los derechos de pueblos indígenas o comunidades étnicas. Basta con el artículo 1 que establece que Colombia es un Estado pluralista, reconociendo con ello la heterogeneidad de culturas, y el respeto por los derechos individuales 
y colectivos, con lo que se busca garantizar la existencia de grupos que comparten una cosmovisión diferente a la de la mayoría (Sánchez-Botero, 1998; Moreno-Parra, s.f. ).

Una sociedad organizada debe estar obligada a brindarle a cada uno de los individuos que la integran una serie de posibilidades para que de manera libre, elija entre ellas la que considere más oportuna para su autodefinición (Gough, 2007). Aun cuando esto contenga factores que nieguen la autodefinición, tales como la imposibilidad de mantener prácticas culturales que construyen la identidad de una comunidad, como lo es en este caso la comunidad negra de San Basilio de Palenque, que conforme a lo contenido en el artículo 1 de la Ley 70 de 1993, son un grupo étnico y, por tanto, es deber del Estado velar por la calidad de vida de estas personas como comunidad, protegiendo su riqueza cultural que se encuentra fundada en bienes tangibles e intangibles alrededor del arroyo (Luna-Galván, Vargas-Chaves \& Guerra-Carrera, 2019). En este sentido, ha logrado coincidir con la Corte Interamericana de Derecho Humanos al estudiar casos relacionados con los territorios de pueblos indígenas o comunidades étnicas, pues ha establecido que la identidad cultural de estos pueblos, en su mayoría tiene como elementos integrantes la relación con las tierras tradicionales y la naturaleza, por cuanto son el medio principal de subsistencia desde el cual se estructura su cosmovisión, religión, imaginarios colectivos, la concepción de la tierra con la que interactúan, y el desarrollo de sus planes de vida, en general, su identidad cultural (Caso Comunidad Indígena Xákmok Kásek. Vs. Paraguay. Fondo, Reparaciones y Costas. Sentencia de 24 de agosto de 2010; Caso Comunidad Indígena Yakye Axa Vs. Paraguay. Fondo Reparaciones y Costas. Sentencia 17 de junio de 2005).

En efecto, dentro de las obligaciones del Estado colombiano, se encuentran las referidas a la protección de las riquezas culturales y naturales de la Nación (Constitución Política de Colombia, artículo 8). Así que luego de examinar las prácticas culturales de la comunidad de San Basilio de 
Palenque en el Arroyo, que habían logrado permanecer en el tiempo, es posible decir que ante la falta de presencia y diligencia del Estado en la prestación de servicios básicos, como el del servicio público de aseo, se ha abierto paso a la existencia de problemas ambientales con el manejo de las basuras y residuos orgánicos en las aguas y orillas del Arroyo.

Estos problemas ambientales, generan daños en la misma naturaleza que repercute de manera directa en los modos de vida de la comunidad de San Basilio de Palenque, que había desarrollado sus prácticas sociales y culturales fundamentadas en la conexión con este sitio comunitario. El detrimento y abandono de los factores ambientales influyen en la falta de interés de la comunidad de acudir a este sitio a realizar cada una de las actividades tradicionales. Por lo tanto, al no haber quien lleve a cabo las actividades que esta comunidad tenía por costumbre realizar, las mismas desaparecen en el tiempo, por lo que se pone en peligro la existencia y subsistencia de la comunidad, en tanto se pierde su identidad y valores ancestrales.

De modo que ante la falta de diligencia del Estado en la solución de un problema ambiental surgido por su misma falta de presencia, es posible hablar de un riesgo de daño cultural en la comunidad de San Basilio de Palenque. Esto debido a que los pobladores dejan sus costumbres y tradiciones para adoptar nuevas nociones culturales y creencias, como consecuencia de los daños ambientales, destruyendo su ancestral relación con la naturaleza.

\section{Conclusiones}

Cuando se trata de conflictos ambientales el daño puede ser material o inmaterial y generar afectaciones de derechos individuales o colectivos. Pero cuando son daños ambientales en territorios de pueblos indígenas o comunidades étnicas, por lo general la afectación recae sobre los derechos colectivos, por la forma en que estas comunidades conciben la naturaleza y el ambiente, así como por su íntima relación con el desarrollo de sus planes de vida.

De ahí que ante la presencia de conflictos ambientales, puede derivarse un conflicto cultural, en tanto se perturba el normal desarrollo 
de las prácticas culturales propias de una comunidad, por el impedimento de realizarlo en el escenario ambiental en el que están acostumbrados, poniéndose en peligro la existencia y subsistencia misma de la comunidad, a causa de la pérdida de identidad cultural.

De allí que es posible afirmar que ante la presencia de un daño ambiental puede derivarse un daño cultural, sobre todo en las comunidades indígenas, tribales y afrocolombianas, por la forma en que estas conciben a la naturaleza y el vínculo cultural intrínseco con el ambiente en el que se encuentran ubicadas en el territorio colombiano.

La comunidad de San Basilio de Palenque está sufriendo un deterioro cultural a raíz de un daño ambiental generado por la falta de presencia estatal, ya que se están dejando de desarrollar actividades sociales, recreativas y culturales en el Arroyo, que era un legado proveniente desde sus ancestros, y poco a poco ha ido perdiendo, entre otros asuntos, la creencia en la existencia de seres mitológicos que habitan mágicamente en la fuente hídrica que nutre a esta comunidad en riesgo.

\section{Referencias}

Beck, Ulrich (1986). La sociedad del Riesgo hacia una Nueva Modernidad. España: Ediciones Paidós Ibérica S.A.

Cabezas Martínez, Juan. 2007. El Daño Cultural en la jurisprudencia de la corte interamericana de Derechos Humanos: ¿nueva categoría jurídica? Revista Jurídica Facultad de Jurisprudencia. N²3, 389-400.

Cafferatta, Néstor (2009). Los principios y reglas del derecho ambiental. Buenos Aires: Programa de Naciones Unidas para el Medio Ambiente. Disponible en: http://web.pnuma.org/gobernanza/documentos/ VIProgramaRegional/3\%20BASES\%20DERECHO\%20AMB/7\%20 Cafferata\%20Principios\%20y\%20reglas\%20del\%20der\%20amb. pdf

Centro de Estudios de Derecho, Justicia y Sociedad - DEJUSTICIA; Organización Nacional Indígena de Colombia - ONIC. 2011. TEJIENDO DERECHOS La reparación a los pueblos indígenas. Recuperado el 09 de febrero de 2019 de www.dejusticia.org/wp-content/ uploads/2017/04/fi_name_recurso_213.pdf 
Corte Interamericana de Derechos Humanos. Caso Efraín Bámaca Vs. Guatemala. Fondo. Sentencia de 25 de noviembre de 2000.

Corte Interamericana de Derechos Humanos. Caso Mayagna Awas Tingni Vs. Nicaragua. Fondo, Reparaciones y Costas. Sentencia de 31 de agosto de 2001

Corte Interamericana de Derechos Humanos. Caso Comunidad Indígena Xákmok Kásek. Vs. Paraguay. Fondo, Reparaciones y Costas. Sentencia de 24 de agosto de 2010;

Corte Interamericana de Derechos Humanos. Caso Comunidad Indígena Yakye Axa Vs. Paraguay. Fondo Reparaciones y Costas. Sentencia 17 de junio de 2005

Gough, I. (2007). El enfoque de las capacidades de M. Nussbaum: un análisis comparado con nuestra teoría de las necesidades humanas. Papeles de relaciones ecosociales y cambio global, 100, 177-202.

Henao, Juan Carlos (2015). Las formas de reparación en la responsabilidad del estado: hacia su unificación sustancial en todas las acciones contra el estado. Revista de Derecho Privado, universidad externado de Colombia, n. ${ }^{\circ}$ 28, pp. 277-366. doi: 10.18601/01234366.n28.10.

Henao, Juan Carlos (2002). Responsabilidad del Estado colombiano por daño ambiental. España: Universidad Europea.

Kymlicka, Will (1996). Ciudadanía Multicultural. Una teoría liberal de los derechos de las minorías. Barcelona: Editorial Paidós.

Luna-Galván, M. \& Vargas-Chaves, I., \& Guerra, L. (2019). Pertinencia de la metodología de enfoque de Sistemas Socio-Ecológicos (SSE) para determinar los actores y sistema de gobernanza en un conflicto ambiental: Estudio de caso del arroyo de San Basilio de Palenque. En: G. Rodríguez \& A. Ibáñez-Elam (Eds.) Las disputas ambientales en Colombia (pp. 239-256). Bogotá: Grupo Editorial Ibáñez.

Mancipe, A. (2005) Los perjuicios inmateriales en la responsabilidad extracontractual del estado en Colombia. Bogotá D.C. Pontificia Universidad Javeriana.

Moreno-Parra, Héctor Alonso (s.f.). Derechos diferenciados y Estado multicultural en Colombia. Colombia: Viva ORG. Disponible en: http:// viva.org.co/cajavirtual/svc0287/pdfs/articulo783_287.pdf 
Organización Internacional del Trabajo (1989). Convenio 169 sobre pueblos indígenas y tribales.

República de Colombia. Congreso de la República. Ley 99 de 1993.

República de Colombia, Consejo de Estado, sentencia de 27 de noviembre de 1990. Expo. 5835.

República de Colombia. Consejo de Estado, Sección Segunda, Sentencia 41001233300020120020601 (15982016), oct. 5/17.

República de Colombia. Corte Constitucional. Sentencia C 224 del 4 de mayo de 2016.

República de Colombia. Corte Constitucional. Sentencia T 622 del 10 de noviembre de 2016.

República de Colombia. Corte Constitucional. Sentencia T 693 del 23 de septiembre de 2011.

Sánchez-Botero, Esther (1998). Justicia y pueblos indígenas de Colombia. La tutela como medio para la construcción de entendimiento intercultural Universidad Nacional: Bogotá: Unijus, Unibiblos

Ternera, L.F. \& Ternera, F. (2008) Breves comentarios sobre el daño y su indemnización. Medellín. Opinión Jurídica, Vol. 7, No. 13, pp. 97 - 112 - ISSN 1692-2530. Universidad del Rosario. 